\title{
25 Transgender and non-binary students, staff, and family members in schools
}

\author{
Clare Bartholomaeus and Damien W. Riggs
}

\section{How to use this policy}

Research shows that schools best meet the needs of transgender and nonbinary students, staff, and family members by proactively developing policies that are implemented before the arrival or disclosure of a transgender or nonbinary person (Baldwin, 2015). Such policies should be both driven and implemented by school leadership and developed in consultation with community members and leaders outside the school who specialise in the needs of transgender and non-binary people. This policy example is intentionally broad, and school policy creators are encouraged to adapt suggestions below to create a policy that best meets the needs of the school context.

[To adapt and use this policy, delete or modify the text as indicated]

\section{[INSERT name of school] The inclusion of transgender and non-binary students, staff, and family members in schools}

\section{Rationale}

Growing numbers of young people are disclosing that they are transgender or non-binary (Clark et al., 2014; Conron et al., 2012). Additionally, other school community members are increasingly disclosing that they are transgender or non-binary, including both staff and parents (Bartholomaeus \& Riggs, 2017). For these diverse populations, inclusion within educational spaces is vital to wellbeing. Historically, educational spaces have either reactively engaged with transgender and non-binary people or have actively sought to exclude this diverse group of people (Baldwin, 2015). Research suggests that inclusion is best facilitated through the proactive development of policies. Such policies should be implemented, updated, and monitored by school staff: it should not be the job of transgender and non-binary people to advocate for their own inclusion. However, transgender and nonbinary people should be actively consulted about their needs, including in terms of updating existing guidelines. 


\section{Purpose}

This policy outlines best practice approaches to affirming transgender and non-binary students, educators, and family members. Central to the policy is the view that transgender and non-binary people have the right to inclusive education and access to inclusive educational spaces.

\section{Scope}

This policy applies to all students, staff, and family members of [INSERT name of school]. It is not relevant whether a transgender or non-binary person is a part of our school community: we believe that all schools should be inclusive of transgender and non-binary people.

[INSERT specific roles and responsibilities of individuals or teams]

\section{Policy statement}

At birth, most people are assigned one of two sexes (female or male). It is normatively expected that gender will be determined by assigned sex, such that those assigned female will identify as such, and those assigned male will identify as such. The term transgender is generally used to refer to people whose gender differs from that normatively expected of their assigned sex at birth. Further, the assumption that there are only two sexes and two genders fails to recognise people with non-binary genders.

The needs of transgender and non-binary people are best met through wholeof-school approaches (Bartholomaeus \& Riggs, 2017). These should not be contingent on transgender or non-binary people being visible or involved with the school. Schools cannot know in advance who may later disclose that they are transgender or non-binary or who may join the school community. More broadly, it is incumbent upon schools to prepare all school community members for engagement with a diverse society. As such, the work of inclusion in regard to transgender and non-binary people is the work of the entire school community.

[INSERT name of school] aims to create spaces where transgender and non-binary people are not simply seen and responded to but are proactively welcomed, included, and respected. [INSERT name of school] ensures the inclusion of transgender and non-binary people through nine key considerations outlined in this policy (Bartholomaeus \& Riggs, 2017).

1 Philosophy and ethos

- Our mission-and-values statement specifically names gender diversity

- Signs and posters are displayed in our school that celebrate gender diversity

2 Policies, procedures, and guidelines

- Bullying, harassment, physical safety, and discrimination: 
a Our policies name gender, gender diversity, and transphobia (including mention of transphobic bullying and language, such as deliberate ongoing use of incorrect names and pronouns)

b Our policies outline consequences for transphobic actions

c Our procedures address dealing with complaints relating to discrimination and harassment

d Our procedures address how to record incidents of transphobic bullying, harassment, and discrimination

- Dress codes:

a Students and staff are free to wear clothes (including uniforms) that reflect their gender, not assigned sex

- Toilets/bathrooms and change rooms:

a Access to toilet/bathroom facilities and change rooms is based on affirmed gender (or individual student or staff preferences)

b Where possible, we endeavour to create all-gender bathrooms

- School camps:

a Transgender and non-binary students are consulted about their preferences for sleeping arrangements when attending school camps. When dividing students by gender is unavoidable, students are placed with other students of their affirmed gender, unless they have concerns and then a suitable arrangement is agreed upon (e.g., placing with friends)

- Physical education and sport:

a Students participating in physical education classes and school sport are not divided by gender. When this is unavoidable students should be grouped according to affirmed gender (or individual student preferences)

b Broader policies may need to be adhered to for interschool sports (although requests may be made to change these)

- Supporting individual transgender and non-binary people:

a Guidelines about how to respond and be affirming when a student, staff member, or parent discloses that they are transgender or non-binary to a staff member are available to staff and parents

b Leeway is provided for students to attend gender-affirming appointments and processes (if relevant) or are required to support family members including siblings (if relevant)

c Procedures for supporting students who have not disclosed to their family or do not have the support of their family, including how to assist students in talking with their families (if desired) are provided to staff 
d Guidelines for disclosing to others in school (if desired by individual) are available and can be modified by the individual student, staff member, or parent

e Guidelines for supporting transgender and non-binary parents and their children are provided to staff

f Guidelines for developing individual support plans for transgender and non-binary students, staff members, and parents are provided to staff

g Guidelines to address possible hostility from community members and media, including the requirement to maintain the privacy of individual students, staff members, and parents, are available

$\mathrm{h}$ There is a process for monitoring, evaluating, implementing, and updating policies

i [INSERT name of school] ensures that the entire school community is aware of policies and has access to them

\section{Leadership}

- The leadership team supports transgender and non-binary students and families, transgender and non-binary staff, and transgender and non-binary parents and families

- The leadership team supports and grants time off for staff training in gender diversity and inclusion, and allocates adequate funding to this professional development

- The leadership team supports educators in teaching about gender diversity and supports transgender and non-binary people both in school and outside of it

- The leadership team seeks support from education departments and unions

- The leadership team is fully aware of education department and other policies and ensures all staff are aware of (new) policies

- There are plans available to the leadership team to provide support in the case of any possible hostility (e.g., from parents, media)

\section{Record keeping}

- Records/enrolment forms remain confidential, with affirmed names and gender used in all other places (depending on student wishes)

- Guidelines for who can access confidential records, with staff having access only to as much information as they need to know, and consequences for privacy breaches is documented

- Modifications to the student database allows for change of gender and records non-binary gender (where this is externally controlled, e. g., by education departments, there may be guidelines for how to do this, otherwise requests for changes to the system to allow this should be made) 
- All identification cards, library cards, and so forth, reflect affirmed names

- All forms are gender-inclusive (e.g., including open-ended response options for gender)

5 Practices and language use

- Inclusive language is used generally

- Staff do not divide students by gender for class activities, sports, subjects, lining up, etc.

- Staff do not address students as "girls and boys"

- All school community members use people's affirmed names and pronouns

- Staff intervene in bullying and keep a record of incidents

- Staff directly challenge transphobic language

- School formals/proms [insert specific social events] are inclusive of all students

$6 \quad$ Resources and training

- Training is available to all staff and people who work or volunteer within our school

- Training is available for administrators and office staff for dealing with media inquiries

- Professional development for educators and school counsellors/psychologists is made available

- Students have access to affirming, supportive, and informed school counsellors/psychologists

- Library resources that reflect gender diversity are available for all to access

- Our school has ongoing contact with relevant support organisations (e.g., Safe Schools programs)

7 Support for school community

- Families and school boards/governing councils have an opportunity to attend information sessions about gender diversity and school changes relating to inclusion through the school year

- Staff have appropriate referral information that allows them to direct cisgender parents of transgender and non-binary children to additional resources and support (or direct them to other staff who have this information)

8 Curriculum/teaching and learning

- All areas of our curriculum are open to including gender diversity content (e.g., literature and language arts, sexuality education, history, civics, mathematics, visual arts) 
- Students have an opportunity to learn about the social construction of gender

- We endeavour to remove all teaching and library sources that are transphobic

9 Transgender-specific initiatives

- Alliance groups (or similar initiatives) that are transgender and nonbinary inclusive are available to students and supported by staff

- Celebration of events such as International Day Against Homophobia, Biphobia, Interphobia and Transphobia (IDAHOBIT), Transgender Day of Visibility, Transgender Day of Remembrance occur within our school

- Materials and resources celebrating gender diversity and/or particular events sought from education departments and support organisations are available to staff and students

- All students and staff at [INSERT name of school] are encouraged to be involved in transgender-specific initiatives, where appropriate

- Students are supported in leading transgender-specific initiatives

\section{Authorship}

Dr Clare Bartholomaeus, Flinders University

Professor Damien W. Riggs, Flinders University

[INSERT RELEVANT STAFF MEMBERS]

\section{Related policy and documents}

[INSERT RELEVANT POLICY AND DOCUMENTS]

American Psychological Association [APA]. (2015). Supporting transgender and gender diverse students in schools: Key recommendations for school administrators. APA. https://www.apa.org/pi/lgbt/programs/safe-supportive/ lgbt/school- administrators.pdf

Anti-Defamation League [ADL]. (2016). Beyond the binary: Discussing transgender and gender non-conformity identity and issues: Suggestions and resources for $\mathrm{K}-12$ teachers. New York: ADL. https://www.adl.org/media/ 4768/download

Australian Children's Television Foundation [ACTF]. (2018). First Day teaching toolkit. ACTF. https://actf.com.au/assets/the_learning_centre/10405/ actf_first_day_teaching_toolkit.pdf

Australian Education Union [AEU]. (2015). Sexual orientation, gender identity and intersex policy. Melbourne: AEU. http://www.aeufederal.org.au/app lication/files/1414/5852/4558/Policy-SOGII2015.pdf 


\section{Rating of evidence base}

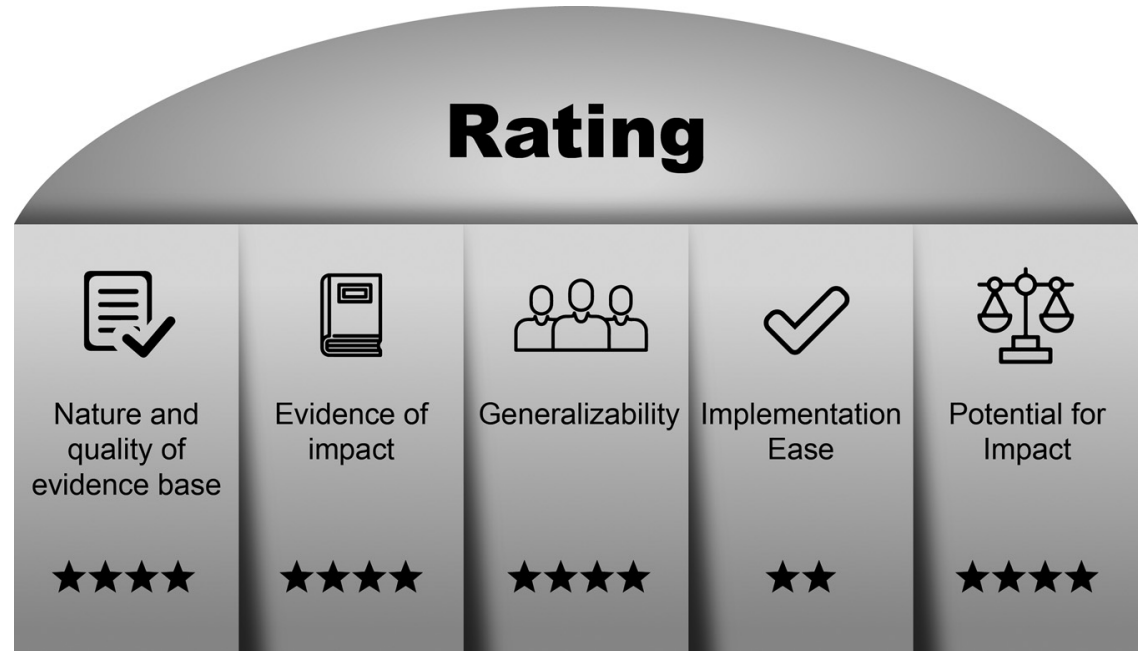

Figure 25.1. Transgender and Non-binary Students, Staff, and Family Members in Schools Rating of Evidence.

Author Note. The literature clearly shows the negative effect of a lack of support upon the wellbeing of transgender and non-binary people in schools. Research has found that the implementation of proactive policies positively impacts transgender and non-binary people. Research has clearly found that educators who are provided with training can better meet the needs of transgender and non-binary students. Historically, research focused more on transgender people with a binary gender; however, increased attention has been paid to people with non-binary genders, allowing for better inclusion based on the evidence. To achieve success in all 9 areas outlined, considerable time and resources are required. Importantly, many resources already exist that can be modified for use in individual schools. Further, it must be acknowledged that implementing the 9 areas may create emotional labour for educational staff (i.e., in terms of educating families and responding to potential negativity). Educational staff will likely require support when implementing the areas, based on the existing evidence base to warrant action. Implementing the 9 areas is highly likely to have a positive impact on transgender and non-binary people.

Cannon, S., \& Best, T. (Eds.). (2015). Schools transgender guidance. The Intercom Trust \& Devon and Cornwall Police. https://www.cornwall.gov.uk/media/ 13620644/schools-transgender_guidance_booklet-2015.pdf

Gender Identity Research and Education Society [GIRES]. (2017). Transition of a teacher in school: Summary of the law and good practice. https://www.gires.org. uk/wp-content/uploads/2014/08/Transition-of-a-Teacher-in-School.pdf

Gender Spectrum. (2017). Confidential: Gender support plan. https://www.acsa. org/application/files/8914/6672/4412/Student_Gender_Support_Plan.030215.pdf Gender Spectrum. (2019). Principles of gender-inclusive puberty and health education. https://gender-spectrum.cdn.prismic.io/gender-spectrum\%2F9ab3b6f1-314 f-4e09-89d8-d5d8adc6511a_genderspectrum_2019_report_web_final.pdf 
InsideOUT. (2016). Making schools safer for trans and gender diverse youth. http://insideout.org.nz/wp-content/uploads/2016/03/Making-Schools-SaferFor-Trans-and-Gender-Diverse-Youth-web.pdf

National Education Union. (2018). Trans educators toolkit. https://neu.org. uk/advice/trans-educators-toolkit

Transcend. (2020). A guide for schools: Information on supporting trans, gender diverse or non-binary students to affirm their gender. https://transcenda us.org/wp-content/uploads/2020/08/Transcend_A-Guide-for-Schools.pdf

Twenty10. (n.d.). A guide to supporting gender diverse, transgender, trans*, genderqueer, and gender questioning young people at school. Newtown: Twenty10. https://www.twenty10.org.au/wp-content/uploads/2016/04/Twenty10s-Guide-toTrans-at-School.pdf

Ward, R., Radcliffe, J., Parsons, M., Gaylard, M., \& Wright Toussaint, D. (2015). Guide to supporting a student to affirm or transition gender identity at school. Safe Schools Coalition. https://studentwellbeinghub.edu.au/media/9548/ guide-to-supporting-a-student-to-affirm-or-transition-gender-identity-at-school_ oct-2015.pdf

\section{Date of ratification}

This policy was ratified on the [INSERT DATE].

\section{Date of review}

This policy will be reviewed by [INSERT DATE].

\section{Further reading}

An extended reading list is available at: http://www.therainbowowl.com

\section{Expert consultation}

It is recommended that schools engage with transgender and non-binary community leaders and young people so as to ensure the currency and relevancy of materials developed. Schools will likely need to engage with their relevant government or private sector organisation to access necessary funding to support implementation and to confirm that guidelines developed are in line with exiting expectations.

\section{References}

Baldwin, D. R. (2015). Parents' experiences as they interact with their transgender children's schools [Unpublished master's thesis]. North Dakota State University. 
Bartholomaeus, C. \& Riggs, D. W. (2017). Transgender people and education. New York: Palgrave Macmillan.

Clark, T. C., Lucassen, M. F. G., Bullen, P., Denny, S. J., Fleming, T. M., Robinson, E. M., et al. (2014). The health and well-being of transgender high school students: Results from the New Zealand adolescent health survey (Youth'12). Journal of Adolescent Health, 55(1), 93-99.

Conron, K. J., Scott, G., Stowell, G. S., \& Landers, S. J. (2012). Transgender health in Massachusetts: Results from a household probability sample of adults. American Journal of Public Health, 102(1), 118-122. 